Original Article

\title{
6-SHOGAOL RICH GINGER OLEORESIN LOADED MIXED MICELLES ENHANCES IN VITRO CYTOTOXICITY ON MCF-7 CELLS AND IN VIVO ANTICANCER ACTIVITY AGAINST DAL CELLS
}

\author{
KIRAN KEMKAR, SATHIYANARAYANAN L.*, ARULMOZHI SATHIYANARAYANAN, KAKASAHEB MAHADIK
}

Bharati Vidyapeeth University, Poona College of Pharmacy, Pune 411038, Maharashtra, India

Email: pharmsathiya@gmail.com

Received: 13 Oct 2017 Revised and Accepted: 22 Nov 2017

\begin{abstract}
Objective: Ginger oleoresin (GO) plays an important role on the attenuation of complications associated to the cancer which is attributed to 6shogaol (6-SGL). The major challenge in using 6-SGL for therapeutic applications is its poor aqueous solubility, low stability in GI and low bioavailability. Considering the potent anticancer nature of 6-SGL and its synergistic activity with other constituents in G0, there is a need to develop a suitable drug delivery system.
\end{abstract}

Methods: Thus in the present study, 6-SGL rich GO (6-SRGO) was incorporated into mixed micelles using phospholipid (Soya Lecithin) as a carrier. The prepared 6-SRGO loaded mixed micelles (6-SRGO-LMM) were characterized physically and chemically using Fourier transform infrared spectroscopy (FTIR), Differential scanning calorimetry (DSC) and further evaluated for stability study, in vitro release study, in vitro cytotoxicity study and in vivo anticancer activity in comparison with 6-SRGO.

Results: The composition such as, drug content (86.27 \pm 1.56$)$, encapsulation efficiency (81.55 \pm 1.05$)$ and particle size (356.11 \pm 4.07$)$ were optimized using $3^{2}$ factorial design. FTIR and DSC study confirm that the 6-SGL from 6-SRGO was entrapped in the core of phospholipid by self-assembly method to form mixed micelles. The 6-SRGO-LMM exhibited significant in vitro (GI50-23.2 $\mathrm{\mu g} / \mathrm{ml}$ ) and in vivo anticancer activity in comparison with 6-SRGO.

Conclusion: We have developed and investigated mixed micelles composed of phospholipids (soya lecithin S80) and SCH as an effective nanocarrier for the delivery of a natural lipophilic anticancer bioactive 6-SGL from 6-SRGO.

Keywords: 6-shogaol, Mixed micelles, Factorial designs, Breast cancer

(C) 2018 The Authors. Published by Innovare Academic Sciences Pvt Ltd. This is an open-access article under the CC BY license (http://creativecommons.org/licenses/by/4.0/) DOI: http://dx.doi.org/10.22159/ijpps.2018v10i1.23077

\section{INTRODUCTION}

Now a day's natural dietary foods including vegetables, fruits, and spices aliments have been achieved a great attraction from the scientist of various healthcare departments, food industries and the normal public because of their safety, efficacy and availability at the comparatively lower price. In addition, they are believed to have no or very less toxic effects than the synthetic drugs $[1,2]$. However, the low aqueous solubility, poor bioavailability, and the stability of phytoconstituents lead to hamper their use in the treatment of various diseases. Therefore, the various delivery system including nanotechnological-based drug-delivery systems has been designed for different naturally occuring phytoconstituents to increase the aqueous solubility and bio-availability and reduce the dose without hampering the efficacy of the drug, safety and the compatibility with patients [3].

6-shogaol rich ginger oleoresin (6-SRGO) is an oleoresin isolated from Zingiber officinale Rosc., consisting of higher content of phenolic ketones; gingerols and shogaols [4-6]. Traditionally they are used for the treatment of a cough, stomach upset, inflammation, hair diseases [7], diarrhoea, nausea and vomiting. Among the various phenolic constituents of ginger oleoresin (GO), the analogs of shogaols and gingerols have been known for their potent antioxidant, anti-inflammatory [8], antimicrobial [9] and anticancer activities [10]. Various studies have discovered that 6-shogaol (6SGL) possesses most potent anticancer activity than the other analogs of shogaols and gingerols [11]. Various in vitro studies have been demonstrated the role of 6-SGL in suppressing the different cancer cells like ovary [12], lungs, colon, gastrointestinal tract and neuroblastoma. The metabolites of 6-SGL are also known to possess anticancer activity $[2,13]$.

The major challenge of using 6-SGL is its poor aqueous solubility; which limits its therapeutic efficacy [10-14]. Besides the high dose of 6-SRGO is required to reach the therapeutic efficacy, which may lead to the several side effects such as diarrhea, nausea and many times the tolerance of the 6-SRGO. There are few attempts have been made to develop nanoformulations using a conventional extract of ginger but detail investigation, characterization and anticancer potential are not reported [15-19]. To overcome these problems present research aims at incorporating 6-SRGO within polymers to develop a drug delivery system displaying enhanced drug solubility, while reducing systemic toxicity of 6 -SRGO.

Mixed micelles; a system for the solubilisation of water-insoluble drugs to increase its efficacy $[20,21]$ is known for its stability and its ability to solubilize maximum amount of water-insoluble drugs in their inner core [22]. Mixed micelles are smaller in size and having outer hydrophilic shell which is responsible for prolonged circulation times in vivo and results in accumulation in the tumoral tissues. Mixed micelles also play an important role in pharmacokinetic and biodistribution behaviour of the drugs [23]. In addition, mixed micelles of 10-400 nm are advantageous for passive targeting into solid tumors by virtue of the enhanced permeability and retention (EPR) effect [24]. Such systems have been applied for delivery of various anticancer drugs such as doxorubicin, propofol, docetaxel and gambogic acid [25-29].

To the best of our knowledge, no previous studies have attempted the preparation of 6-SRGO-loaded mixed micelles (LMM) to improve its anticancer efficacy. Therefore, this study was attempted to investigate the potentials of 6-shogaol rich ginger oleoresin-loaded mixed micelles (6-SRGO-LMM), to enhance solubility, physiological stability and anticancer efficiency.

\section{MATERIALS AND METHODS}

\section{Materials}

Mixed micelles were produced using a carrier Phospholipid that was supplied by Cologne, Germany, with a melting point at $100{ }^{\circ} \mathrm{C}$. The reference standard (pure isolated) of 6 -shogaol ( $>96 \%$ purity $\mathrm{w} / \mathrm{w}$ ) 
was purchased from Natural Remedies Pvt. Ltd. Bangalore, Karnataka, India. 6-SRGO was purchased from Nisarg Biotech, Satara, Maharashtra, India, which is totally free from any endotoxins. Dialysis bags (MW cut-off 12,000) were purchased from Sigma-Aldrich Chemical Private Ltd (Bangalore, India). The needed chemicals and reagents (analytical grade) used in this research work are purchased from Merck Specialties Private Limited, Mumbai, India.

\section{Quantification of 6-SGL present in GO}

6-shogaol present in ginger oleoresin was quantified using an RPHPLC method which was reported in our earlier study [30].

\section{Preparation of 6-SRGO-LMM}

6-SRGO-LMM was prepared according to self-assembly method [31]. Extraction of 6-SGL was performed by adding the GO to a dehydrated ethanol containing a specific amount of phospholipid followed by mixing with a suitable quantity of sodium cholate hydrated $(\mathrm{SCH})$ under stirring at room temperature. Sufficient distilled water was added under magnetic stirring at $2000 \mathrm{rpm}$ for $45 \mathrm{~min}$ followed by sonication for $10 \mathrm{~min}$ to obtain $10 \mathrm{ml}$ of the mixed micellar suspension. Blank mixed micelles (devoid of 6-SRGO) were prepared in a similar manner.

\section{Optimization of 6-SRGO-LMM by $3^{2}$ factorial designs}

$3^{2}$ factorial designs were adopted to optimize the micelle composition while studying the effect of phospholipid and $\mathrm{SCH}$ (independent variables) on Drug Content (DC), Entrapment Efficiency (EE) and Particle Size (PS) (three dependent variables or responses) by obtaining a response surface plot.

\section{Characterization of 6-SRGO-LMM}

\section{Micelles size distribution and zeta potential}

The laser diffraction technique was used to determine the size of blank and 6-SRGO-LMM (Malvern 2000 SM; Malvern Instruments, Malvern, UK). The laser Doppler electrophoretic mobility measurements (Zetasizer 3000, Malvern Instruments) were done to measure the zeta potential at $25^{\circ} \mathrm{C}$.

\section{DC and EE}

The concentration of 6-SGL in the mixed micelles was determined by rapid and sensitive RP-HPLC method. The superficial 6-SGL was determined by washing 6-SRGO-LMM with ethanol and measuring the 6-SGL content collected in the washing solution. EE was determined as the ratio between the encapsulated 6-SGL (total - superficial) and the feeding 6-SGL. The DC was determined as the ratio between the micelles collected at the end of the process and the mass of carrier added to 6-SRGO used in the preparation of micelles.

\section{Physical characterization}

\section{Fourier transform infrared spectroscopy (FTIR)}

The pure 6-SRGO and 6-SRGO-LMM were characterized by FTIR spectroscopy in the 4000 to $400 \mathrm{~cm} 1$ region using FTIR Spectrophotometer (Jasco 4100).

\section{Differential scanning calorimetry (DSC)}

DSC was done to perform the thermal analysis of 6-SRGO and 6-SRGOLMM by using DSC 821, Mettler Toledo instrument. Near about $5 \mathrm{mg}$ of 6-SRGO-LMM were heated in a hermetically sealed aluminium pan with heating rate $10{ }^{\circ} \mathrm{C}$ per min under a nitrogen atmosphere (flow rate $50 \mathrm{ml} / \mathrm{min}$ ). 6-SRGO was also analyzed for comparison.

\section{Surface morphology}

The morphology of 6-SRGO-LMM was performed using transmission electron microscopy (TEM). The sample preparation for the TEM was performed following the method reported in [3].

\section{Evaluation of 6-SRGO-LMM stability}

6-SRGO-LMM were transferred in glass containers and stored at $25^{\circ} \mathrm{C}$, protected from the light for $90 \mathrm{~d}$ to evaluate short-term stability studies. Micelles were evaluated with respect to the amount of 6SGL, PS and EE.

\section{In vitro release of 6-SRGO-LMM}

The in vitro release of 6-SRGO-LMM was carried out in $0.1 \mathrm{~N} \mathrm{HCL} \mathrm{(pH}$ 1.2) and in phosphate-buffer (pH 7.4) using dialysis bag diffusion technique [3]. A formulation equivalent to $1 \mathrm{mg}$ of 6-SRGO or $1 \mathrm{mg}$ 6-SRGO solution $(1 \mathrm{mg} / \mathrm{ml}$ in $50 \% \mathrm{w} / \mathrm{w}$ mixture of PEG 400 and water) as control was incorporated into a dialysis bag (cellulose membrane, MW cut-off $12,000 \mathrm{Da}$ ), sealed and incorporated into 50 $\mathrm{ml}$ of release medium. The temperature of the entire system was maintained at $37 \pm 0.5{ }^{\circ} \mathrm{C}$ with constant magnetic stirring at 100 $\mathrm{rpm} / \mathrm{min}$. At previously planned time intervals, the sample was removed and replaced with an equal volume of fresh medium in order to maintain sink conditions. 6-SGL present in the solution was quantified by using rapid and sensitive RP-HPLC method. Analysis of data was performed using PCP Disso software (V3; Poona College of Pharmacy, Pune, India).

\section{In vitro cytotoxicity study}

In vitro cytotoxicity study of free 6-SRGO, blank mixed micelles and 6-SRGO-LMM were evaluated against human breast cancer MCF-7 using in vitro SRB assay at Advanced Centre for Treatment, Research and Education in Cancer (ACTREC), Mumbai. The results of MCF-7 were compared with that of marketed Adriamycin (Doxorubicin). The cytotoxicity protocol for SRB assay was followed by the method described by [3].

\section{Acute toxicity study}

The acute toxicity study was performed for 6-SRGO and 6-SRGOLMM on swiss albino mice. The animals were randomly divided into eleven groups $(n=6)$. The first group (control group) received feed and distilled water orally. Groups 2-6 were orally treated with 6SRGO with doses $55 \mathrm{mg} / \mathrm{kg}, 175 \mathrm{mg} / \mathrm{kg}, 550 \mathrm{mg} / \mathrm{kg}, 1750 \mathrm{mg} / \mathrm{kg}$ and $2000 \mathrm{mg} / \mathrm{kg}$ body weight, respectively. Groups $7-11$ were orally treated with 6-SRGO-LMM with doses $55 \mathrm{mg} / \mathrm{kg}, 175 \mathrm{mg} / \mathrm{kg}, 550$ $\mathrm{mg} / \mathrm{kg}, 1750 \mathrm{mg} / \mathrm{kg}$ and $2000 \mathrm{mg} / \mathrm{kg}$ body weight, respectively. The animals were continuously observed for general behavioural changes, a sign of toxicity, and mortality for $1 \mathrm{~h}$ after treatment and then intermittently for $4 \mathrm{~h}$ and thereafter over a period of $24 \mathrm{~h}$. Mice were further observed for up to $14 \mathrm{~d}$ for behavioural change and sign of toxicity.

In vivo anticancer activity of 6-SRGO and 6-SRGO-LMM against Dalton's Ascitic Lymphoma (DAL) in mice

Male Swiss albino mice having the weight range of $20 \mathrm{gm}$ to $25 \mathrm{gm}$ were used for the study. They were kept in to micro nylon boxes at control temperature (temp $25 \pm 2^{\circ} \mathrm{C}$ ). The experimental protocol was approved by the Institutional Animal Ethics Committee (IAEC) constituted in accordance with the rules and guidelines of the Committee for the Purpose of Control and Supervision on Experimental Animals (CPCSEA), India (Approved protocol noCPCSEA/Q. A./01/2014-15; institutional approval no-CPCSEA/ 1999/100).

\section{Induction of cancer cells}

DLA cells were procured from Amala cancer research center, Trissur, Kerala, India. The cancer cells were implanted in vivo in mice by intraperitoneal route. Before transferring the cancerous cells to mice, by using saline solution the DLA cells were taken from the peritoneal cavity of the mice. The total cells count was maintained up to $1 \times 10^{6}$ after dilution and was given intraperitoneally. The treatment was started after seven days of induction of tumor cells $[32,33]$.

\section{Grouping of the mice and outline of the treatment}

Animals were grouped into nine groups with each group contains six animals. The animals of eight groups (group 2-8) received DLA cells ( 1 x $10^{6}$ cells per mice), and group 1 was kept as a control group.

Group 1 and 2 represents normal control and tumor control respectively. 
Group 3 represents positive control, (Received 5-fluorouracil injection at $20 \mathrm{mg} / \mathrm{kg}$ body weight, orally).

Group 4, 5 and 6 represents treatment control, (Received 6-SRGO at the doses of $100 \mathrm{mg} / \mathrm{kg}, 200 \mathrm{mg} / \mathrm{kg}$ and $400 \mathrm{mg} / \mathrm{kg}$ body weight respectively orally).

Group 7, 8 and 9 represents treatment control group, (Received 6SRGO-LMM at the doses of $100 \mathrm{mg} / \mathrm{kg}, 200 \mathrm{mg} / \mathrm{kg}$ and $400 \mathrm{mg} / \mathrm{kg}$ body weight respectively orally).

\section{Evaluation of clinical parameters}

During this study, the cancer cells were inoculated into the animals and the treatment for that cancer was started after $24 \mathrm{~h}$ one time a day for $14 \mathrm{~d}$. Once after all the doses were finished, the animals were sacrificed by euthanasia. The samples of the blood were withdrawn from each mouse at predetermined time from retro-orbital plexus bleeding. Various parameters were checked which include, count of the cancer cells, hematological parameters consist of the content of $\mathrm{Hb}, \mathrm{RBC}$ count, WBC count, platelet count and the volume of packed cells. Serum enzyme and the lipid profile include a count of total cholesterol (TC), triglycerides (TG), aspartate aminotransferase (AST), alanine aminotransferase (ALT) and alkaline phosphatase (ALP) and the derived parameters such as total lifespan (\%) of the animal, body weight of the animal used and the cancer cell count.

\section{Statistical analysis}

All data are expressed as means \pm SEM. One way ANOVA followed by Dunnetts post-test was used for in vivo anticancer activity. $\mathrm{P}<0.01$ was considered as significant. Prism 5 Demo software has been used for the statistical analysis.

\section{RESULTS}

We have developed and investigated mixed micelles composed of phospholipids (soyalecithin S80) and SCH as an effective nanocarrier for the delivery of a natural lipophilic anticancer bioactive 6-SGL from 6-SRGO to enhance both in vitro cytotoxicity and in vivo anticancer activity of 6-SGL.

\section{Quantification of 6-SGL present in GO}

In the present study 6-SGL present in the GO was quantified by rapid and sensitive RP-HPLC method and the 6-SGL was quantified at a retention time of $10.30 \mathrm{~min}$ at the wavelength $281 \mathrm{~nm}$ (fig. 1). The amount of 6-SGL present in 6-SRGO was found to be $20 \% \pm 2 \%$ whereas the optimized formulation 6-SRGO-LMM was found to have $16 \% \pm 1 \%$ when compare to the pure isolated 6 -SGL.

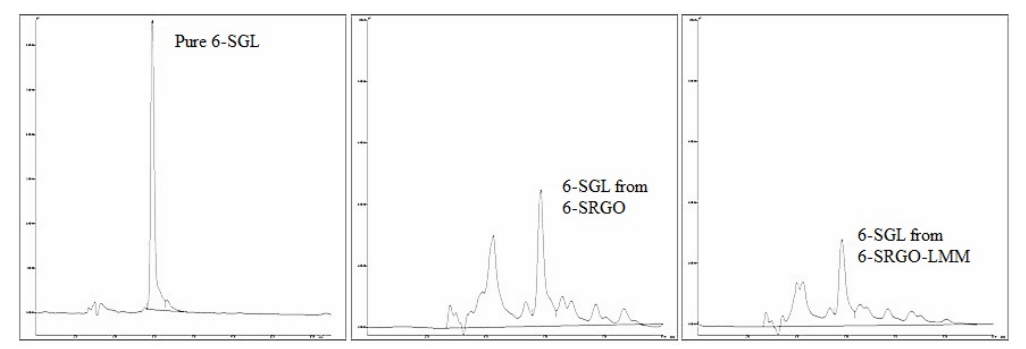

Fig. 1: HPLC chromatograms of pure 6-SGL (A), 6-SGL from 6SRGO (B) and 6-SGL from 6-SRGO-LMM (C) formulation

\section{Preparation and optimization of 6-SRGO-LMM by $3^{2}$ factorial designs}

6-SRGO-LMM was produced and the effect of these prepared mixed micelles composition on DC, EE and PS was studied by $3^{2}$ factorial designs [34]. The mean PS was observed in between $300-400 \mathrm{~nm}$ and was affected by the selected variables $(\mathrm{r} 2=$ 0.9247).

The DC and EE were in the range of $78-97 \%$ and $70-89 \%$ respectively. A good fit $(\mathrm{r} 2$ for $\mathrm{DC}=0.7656$ and $\mathrm{EE}=0.8875)$ was observed between the DC, EE and the independent variables.

\section{Fourier transform infrared spectroscopy}

In the IR spectra of 6-SRGO (fig. 2A), following peaks are assigned,$\mathrm{OH}$ stretching $(\sim 3124 \mathrm{em})$, Aromatic $-\mathrm{CH}$ stretching $(\sim 2994$ $\mathrm{cm}-1)$, Aliphatic-CH stretching $(\sim 2852-\mathrm{eth}), \quad-\mathrm{C}=0$ stretching $(\sim 1736 \mathrm{~cm}-1)$ and $\mathrm{OH}$ bending out of the plan $(\sim 1373 \mathrm{~cm}-1)$, while in 6-SRGO-LMM (fig. 2C), 6-SRGO incorporated with polymer phospholipid, the remarkable peak of an active drug such as- $\mathrm{C}=0$ ketone stretching and- $\mathrm{OH}$ bending were not seen.

\section{Differential scanning calorimetry}

6-SRGO-LMM and 6-SRGO were analyzed by Differential scanning calorimetry to determine the onset, maximum temperature and enthalpy (table 1 and fig. 3 ).

Table 1: Differential scanning calorimetry analysis

\begin{tabular}{lll}
\hline & A & B \\
\hline Peak $\left({ }^{\circ} \mathrm{C}\right)$ & 240.65 & 148.26 \\
Onset $\left({ }^{\circ} \mathrm{C}\right)$ & 223.87 & 135.51 \\
Enthalpy $(\mathrm{J} / \mathrm{g})$ & 31.11 & 56.74 \\
\hline
\end{tabular}

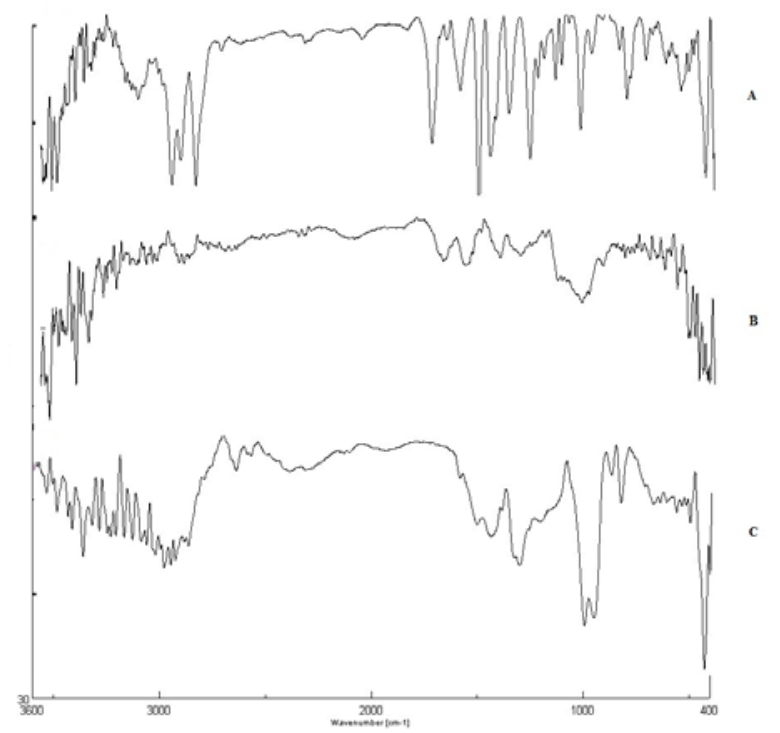

Fig. 2: Fourier transform infrared (FT/IR) spectroscopy analyses of (C) 6-SRGO-LMM, compared with (A) 6-SRGO and (B) Phospholipid

\section{Surface morphology}

The obtained 6-SRGO-LMM solution appeared clear and light yellowish in color (fig. 4). The fig. also shows the suspension of pure 6-SRGO dispersed in water at the same drug concentration similar to that reported in the literature [35]. 


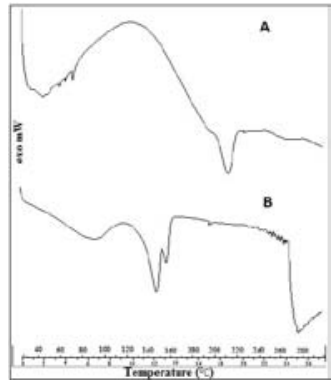

Fig. 3: Differential scanning calorimetry (DSC) analyses of (A) 6SRGO and (B) 6-SRGO-LMM
Fig. revealed that the prepared formulation was monodispersed, tightly packed and spherical shaped mixed micelles whose size measured by laser scattering technique was correlated well with that by TEM.

\section{Evaluation of 6-SRGO-LMM stability}

Stability study reveals that 6-SRGO-LMM did not show noticeable changes in their size $(340 \pm 15 \mathrm{~nm})$ and EE $(89 \pm 2.01 \%)$. The sedimentation of the drug was not observed during short-term stability studies. A drug loss of meager $3.62 \%$ was probably due to the partial decomposition of 6-SGL.

This indicated that the drug-loaded micelles were physically stable at room temperature for at least $3 \mathrm{mo}$.

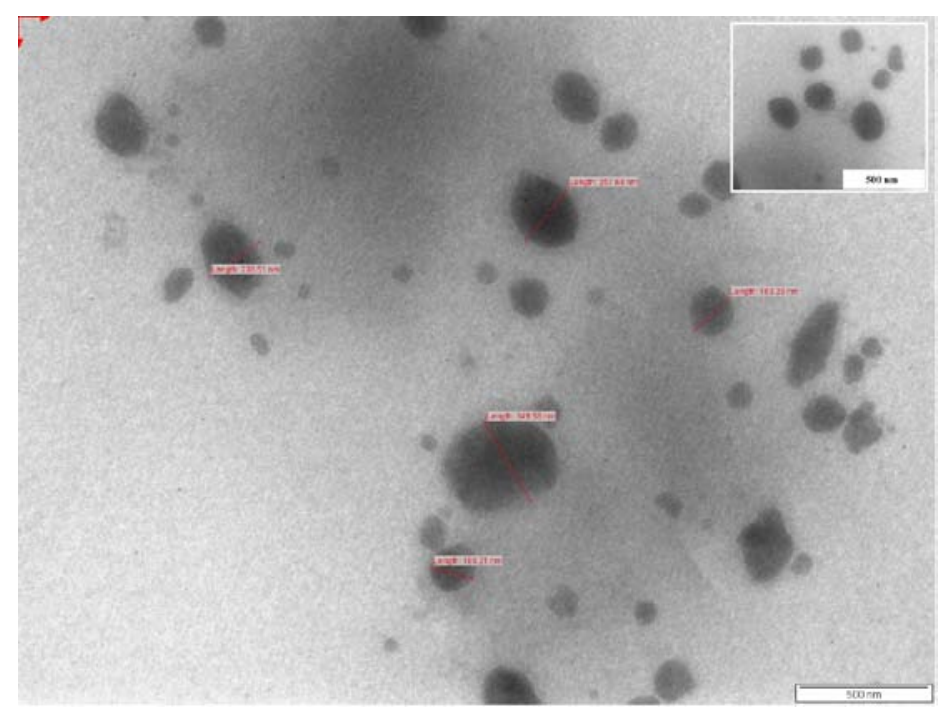

Fig. 4: Transmission electron micrograph of optimized 6-SRGO-LMM

\section{In vitro release study}

The dialysis method is the most suitable method that simulated the circumstance of drug in vivo. The release pattern of 6-SGL from 6SRGO-LMM in comparison with 6-SGL from 6-SRGO was investigated in gastric fluids ( $\mathrm{pH} 1.2$ ), and intestinal fluids (pH 7.4). Fig. 5 showed the dissolution profile of 6-SGL from 6-SRGO-LMM and 6-SRGO in both $\mathrm{HCl}(\mathrm{pH} 1.2)$ and phosphate buffer saline (pH 7.4), respectively. 6-SGL release from the mixed micellar system was always slower than the corresponding 6-SGL from 6-SRGO escaped rapidly from the dialysis bag approximately $60 \%$ within $2 \mathrm{~h}$ and the release was over $95 \%$ by $6 \mathrm{~h}$. The profile of the 6-SRGO-LMM showed a very slow release of 6-SGL approximately $30 \%$ within $2 \mathrm{~h}$ and the release was over $95 \%$ by $42 \mathrm{~h}$.

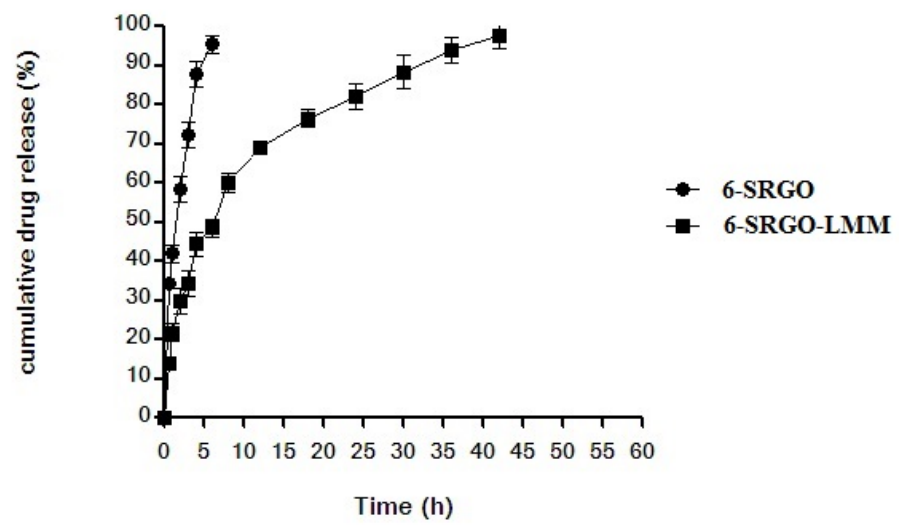

Fig. 5: In vitro release profiles of 6-SGL from 6-SRGO and from 6-SRGO-LMM

\section{In vitro anticancer activity}

The in vitro anticancer activity of 6SRGO-LMM was investigated and compared with the free drug in solution, blank mixed micelles and marketed Adriamycin (Doxorubicin) against human breast cancer MCF-7 cells using in vitro SRB assay. The results illustrated in table 2 , indicated that 6SRGO-LMM displayed better cytotoxic activity than the 6-SRGO and the blank mixed micelles. The total growth 
inhibition concentration against MCF-7 was found to be 23.2 $\mu \mathrm{g} / \mathrm{ml}, 26.8 \mu \mathrm{g} / \mathrm{ml}$ and $>80 \mu \mathrm{g} / \mathrm{ml}$ for 6-SRGO-LMM, 6-SRGO and blank respectively. LC50 against MCF-7 of 6-SRGO-LMM was $>80$ $\mu \mathrm{g} / \mathrm{ml}$, whereas free 6-SGL from GO in solution and blank mixed micelles showed $>80 \mu \mathrm{g} / \mathrm{ml}$. The representative images are shown in fig. 6.

Table 2: In vitro cytotoxic effect of 6-SRGO-LMM on MCF-7 breast cancer cells

\begin{tabular}{llll}
\hline & Drug concentration $(\mu \mathrm{g} / \mathbf{m l})$ calculated from graph & GI50 \\
\hline MCF 7 & LC50 & TGI & 26.8 \\
6-SRGO & $>80$ & 56.4 & $>80$ \\
Blank & $>80$ & $>80$ & 23.2 \\
6-SRGO-LMM & $>80$ & 55.9 & $<10$ \\
ADR & 60.8 & 29.5 & \\
\hline
\end{tabular}

Each point represents an average $\pm \operatorname{SD}(n=3)$.
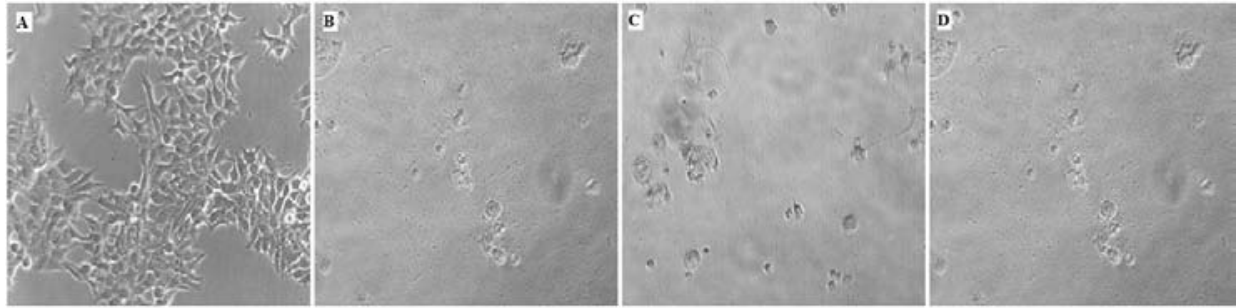

Fig. 6: In vitro cytotoxicity study on the breast cancer cell line (MCF 7), (A) MCF 7 control, (B) Treatment control, (C) Treated with 6-SRG0, (D) treated with 6-SRGO-LMM

\section{Acute toxicity study}

No death or toxic effect on tested animals were recorded during first $24 \mathrm{~h}$ as well as $14 \mathrm{~d}$ of observation after oral treatment of 6-SRGO and 6-SRGO-LMM at the doses of $55 \mathrm{mg} / \mathrm{kg}, 175 \mathrm{mg} / \mathrm{kg}, 550 \mathrm{mg} / \mathrm{kg}$, $1750 \mathrm{mg} / \mathrm{kg}$ and $2000 \mathrm{mg} / \mathrm{kg}$ body weight.

\section{In vivo anticancer activity of 6-SRGO and 6-SRGO-LMM against} dalton's ascitic lymphoma (DAL) in mice

In the in vivo anticancer activity, the average lifespan of tumor control group of animals was found to be $48 \%$ whereas an increase in life span was observed up to $78 \%, 81 \%$ and $84 \%$ for group treated with 6-SRGO at the doses of 100, 200 and $400 \mathrm{mg} / \mathrm{kg}$ body weight and $88.5 \%, 89.5 \%$ and $90.5 \%$ for group treated with 6-SRGOLMM at the doses of 100,200 and $400 \mathrm{mg} / \mathrm{kg}$ body weight respectively.

However, in group treated with 5-FU the overall life span of the animals was found to be $94 \%$, which shows the very potent cytotoxic nature of 5-FU [36].

As shown in table 3, except the WBC count, all other hematological parameters have been decreased significantly for groups treated with 6-SRGO-LMM than the groups treated with 6-SRGO at all three doses, compared to normal control group of animals.

Table 3: Effect of 6-SRGO and 6-SRGO-LMM on hematological parameters

\begin{tabular}{|c|c|c|c|c|c|}
\hline Treatment & Total WBC cells/mlx10 ${ }^{3}$ & Rbc count mill/cumm & $\mathrm{Hb}$ gm/dl & PCV \% & Platelets lakhs/cumm \\
\hline $\mathrm{G}_{1}$ & $10.35 \pm 1.30$ & $4.30 \pm 1.85$ & $12.50 \pm 1.34$ & $14.25 \pm 2.44$ & $3.30 \pm 0.95$ \\
\hline $\mathrm{G}_{2}$ & $15.22 \pm 2.64^{\mathrm{a}^{* *}}$ & $2.68 \pm 0.72^{\mathrm{a}^{* *}}$ & $6.80 \pm 0.95^{\mathrm{a}^{* *}}$ & $38.36 \pm 3.35^{\mathrm{a}^{* *}}$ & $1.70 \pm 0.42^{\mathrm{a}^{* *}}$ \\
\hline $\mathrm{G}_{3}$ & $12.32 \pm 1.30^{\mathrm{b} * *}$ & $4.05 \pm 1.40^{\mathrm{b}^{* *}}$ & $11.90 \pm 1.48^{\mathrm{b}^{* *}}$ & $16.40 \pm 1.40^{\mathrm{b} * *}$ & $2.94 \pm 0.65^{b^{* *}}$ \\
\hline $\mathrm{G}_{4}$ & $12.90 \pm 2.04 \mathrm{~b}^{* *}$ & $3.45 \pm 1.05^{b^{* *}}$ & $11.60 \pm 1.22^{\mathrm{b}^{* *}}$ & $17.34 \pm 2.30^{\mathrm{b} * *}$ & $2.88 \pm 0.54 \mathrm{~b}^{* *}$ \\
\hline $\mathrm{G}_{5}$ & $13.08 \pm 2.26^{\mathrm{b}^{* *}}$ & $3.85 \pm 1.34^{\mathrm{b}^{* *}}$ & $12.35 \pm 1.66^{\mathrm{b}^{* *}}$ & $18.08 \pm 2.66^{\mathrm{b}^{* *}}$ & $3.04 \pm 0.68^{b^{* *}}$ \\
\hline $\mathrm{G}_{6}$ & $12.66 \pm 2.28^{\mathrm{b}^{* *}}$ & $4.10 \pm 1.45^{b^{* *}}$ & $12.15 \pm 1.36^{b^{* *}}$ & $17.84 \pm 2.46^{\mathrm{b}^{* *}}$ & $2.94 \pm 0.62^{\mathrm{b}^{* *}}$ \\
\hline $\mathrm{G}_{7}$ & $12.34 \pm 1.55^{\mathrm{b}^{* *}}$ & $4.06 \pm 1.72^{\mathrm{b}^{* *}}$ & $12.24 \pm 1.55^{\mathrm{b}^{* *}}$ & $17.38 \pm 2.40^{\mathrm{b} * *}$ & $3.26 \pm 0.84^{\mathrm{b} * *}$ \\
\hline $\mathrm{G}_{8}$ & $12.22 \pm 1.50^{\mathrm{b} * *}$ & $4.10 \pm 1.75^{\mathrm{b}^{* *}}$ & $12.28 \pm 1.58^{\mathrm{b}^{* *}}$ & $17.30 \pm 2.35^{\mathrm{b}^{* *}}$ & $3.30 \pm 0.86^{\mathrm{b}^{* *}}$ \\
\hline $\mathrm{G}_{9}$ & $11.80 \pm 1.42^{\mathrm{b}^{* *}}$ & $4.15 \pm 1.78^{\mathrm{b}^{* *}}$ & $12.35 \pm 1.62^{\mathrm{b}^{* *}}$ & $17.26 \pm 2.30^{\mathrm{b} * *}$ & $3.35 \pm 0.88^{\mathrm{b}^{* *}}$ \\
\hline
\end{tabular}

$\mathrm{G}_{1}$-Normal Control, $\mathrm{G}_{2}$-Cancer Control, $\mathrm{G}_{3}$-Positive control, $\mathrm{G}_{4}$ to $\mathrm{G}_{6}$-Treatment control 6-SRGO 100,200,400 mg/kg, $\mathrm{G}_{7}$ to $\mathrm{G}_{9}-\mathrm{Treatment}$ control (6-SRGO-LMM 100,200,400 mg/kg), All values are expressed as mean \pm SEM for 6 animals in each group and results were analyzed by using One way ANNOVA, followed by Dunnetts post test, ${ }^{a^{*}}$ Values are significantly different from normal control $\left(\mathrm{G}_{1}\right)$ at $\mathrm{P}<0.01$, $^{\mathrm{b}^{*}}$ Values are significantly different from cancer control $\left(\mathrm{G}_{2}\right)$ at $\mathrm{P}<0.01$

The induction of DLA cells, rises the level of cholesterol, aspartate aminotransferase, alanine aminotransferase and alkaline phosphatase to the significant level when compared to the normal group. The treatment with 6-SRGO-LMM recovers the above mentioned changes to the normal level than the groups treated with 6-SRGO at all three doses (table 3).

Packed cell volume, as well as viable tumor cell counts, were reduced in the group treated with 6-SRGO-LMM more significantly than the groups treated with 6-SRGO at all three doses when compared to tumor control groups (table 4 and 5).

\section{DISCUSSION}

6-SGL from ginger has been well established for its anticancer potential. However, its usage as a therapeutic anticancer agent is limited due to its poor water solubility and bioavailability. As per the best knowledge of authors, 6-SGL in pure form is reported to be unstable in simulated gastric and intestinal fluids in GI [37], thus expected to be unstable when administered orally. At the best of our knowledge, there have been no studies reported to formulate 6-SGL to solve the above problems. Obtaining pure compound from herbals by tedious isolation processes and formulating them are quite expensive, 
moreover, single phytocompounds in most cases exhibit less pharmacological activities than when administer in the form of enriched extracts due to synergistic activity. Thus in present study, an attempt has been made to formulate the 6-SRGO-LMM composed of phospholipid (soya lecithin S80) and SCH as an effective nanocarrier for the delivery of a natural lipophilic anticancer bioactive 6-SGL.

Table 4: Effect of 6-SRGO and 6-SRGO-LMM on serum enzymes and lipid proteins

\begin{tabular}{|c|c|c|c|c|c|}
\hline Treatment & Cholesterol (mg/dl) & TGL (mg/dl) & AST (U/l) & ALT (U/l) & $\operatorname{ALP}(U / 1)$ \\
\hline$\overline{\mathrm{G}_{1}}$ & $110.085 \pm 3.05$ & $136.85 \pm 2.55$ & $38.40 \pm 1.65$ & $33.28 \pm 1.45$ & $132.28 \pm 2.40$ \\
\hline $\mathrm{G}_{2}$ & $146.95 \pm 4.34^{\mathrm{a}^{* *}}$ & $220.28 \pm 4.40^{\mathrm{a}^{* *}}$ & $78.6 \pm 2.74 \mathrm{a}^{* *}$ & $62.32 \pm 2.60^{\mathrm{a}^{* *}}$ & $265.30 \pm 4.35^{\mathrm{a}^{* *}}$ \\
\hline $\mathrm{G}_{3}$ & $126.30 \pm 3.84^{\mathrm{b}^{* *}}$ & $169.15 \pm 2.65^{b^{* *}}$ & $44.40 \pm 1.72^{\mathrm{b}^{* *}}$ & $34.52 \pm 1.70^{\mathrm{b}^{* *}}$ & $154.45 \pm 2.40^{\mathrm{b} * *}$ \\
\hline $\mathrm{G}_{4}$ & $123.44 \pm 3.64^{b^{* *}}$ & $172.32 \pm 2.84^{\mathrm{b}^{* *}}$ & $50.15 \pm 2.82^{\mathrm{b}^{* *}}$ & $40.35 \pm 2.02^{\mathrm{b}^{* *}}$ & $171.85 \pm 2.90^{\mathrm{b} * *}$ \\
\hline $\mathrm{G}_{5}$ & $122.30 \pm 3.60^{\mathrm{b}^{* *}}$ & $166.15 \pm 2.56^{\mathrm{b}^{* *}}$ & $49.05 \pm 2.32^{\mathrm{b}^{* *}}$ & $36.84 \pm 1.86^{\mathrm{b}^{* *}}$ & $172.35 \pm 2.94^{\mathrm{b} * *}$ \\
\hline $\mathrm{G}_{6}$ & $114.20 \pm 3.52^{\mathrm{b}^{* *}}$ & $171.80 \pm 2.76^{b^{* *}}$ & $46.50 \pm 2.20^{\mathrm{b}^{* *}}$ & $37.35 \pm 1.94^{\mathrm{b} * *}$ & $167.34 \pm 2.36^{b^{* *}}$ \\
\hline $\mathrm{G}_{7}$ & $118.30 \pm 3.50^{\mathrm{b}^{* *}}$ & $164.25 \pm 2.72^{\mathrm{b}^{* *}}$ & $43.32 \pm 2.344^{\mathrm{b}^{* *}}$ & $35.32 \pm 1.58^{\mathrm{b}^{* *}}$ & $164.20 \pm 2.30^{\mathrm{b} * *}$ \\
\hline $\mathrm{G}_{8}$ & $116.44 \pm 3.46^{\mathrm{b}^{* *}}$ & $163.32 \pm 2.70^{\mathrm{b}^{* *}}$ & $42.35 \pm 2.34^{\mathrm{b}^{* *}}$ & $34.92 \pm 1.52^{\mathrm{b}^{* *}}$ & $162.16 \pm 2.22^{\mathrm{b} * *}$ \\
\hline $\mathrm{G}_{9}$ & $114.52 \pm 3.40^{\mathrm{b}^{* *}}$ & $158.30 \pm 2.48^{\mathrm{b}^{* *}}$ & $41.95 \pm 2.22^{\mathrm{b}^{* *}}$ & $34.60 \pm 1.46^{\mathrm{b}^{* *}}$ & $160.22 \pm 2.18^{\mathrm{b} * *}$ \\
\hline
\end{tabular}

$\mathrm{G}_{1}$-Normal Control, $\mathrm{G}_{2}$-Cancer Control, $\mathrm{G}_{3}$-Positive control, $\mathrm{G}_{4}$ to $\mathrm{G}_{6}$-Treatment control 6-SRGO 100,200,400 mg/kg, $\mathrm{G}_{7}$ to $\mathrm{G}_{9}$-Treatment control 6-SRGO-LMM 100,200,400 mg/kg, All values are expressed as mean \pm SEM for 6 animals in each group and results were analyzed by using One way ANNOVA, followed by Dunnetts post test, ${ }^{a^{* *}}$ Values are significantly different from normal control $\left(\mathrm{G}_{1}\right)$ at $\mathrm{P}<0.01, \mathrm{~b}^{* *}$ Values are significantly different from cancer control $\left(\mathrm{G}_{2}\right)$ at $\mathrm{P}<0.01$

Table 5: Effect of 6-SRGO and 6-SRGO-LMM on the life span, body weight and cancer cell count of tumor induced mice

\begin{tabular}{lllll}
\hline Treatment & Number of animals & \% ILS life span & Increase in body weight grams & Cancer cell count ml X 10 $^{\mathbf{6}}$ \\
\hline $\mathrm{G}_{1}$ & 6 & $>>30 \mathrm{~d}$ & $2.22 \pm 0.68$ & - \\
$\mathrm{G}_{2}$ & 6 & $48 \%$ & $9.44 \pm 1.86^{\mathrm{a}^{* *}}$ & $2.75 \pm 0.80^{\mathrm{a}^{* *}}$ \\
$\mathrm{G}_{3}$ & 6 & $94 \%$ & $5.66 \pm 0.42^{\mathrm{b}^{* *}}$ & $1.30 \pm 0.22^{\mathrm{b}^{* *}}$ \\
$\mathrm{G}_{4}$ & 6 & $78 \%$ & $5.98 \pm 0.84^{\mathrm{b}^{* *}}$ & $1.66 \pm 0.50^{\mathrm{b}^{* *}}$ \\
$\mathrm{G}_{5}$ & 6 & $81 \%$ & $6.05 \pm 0.88^{\mathrm{b}^{* *}}$ & $1.38 \pm 0.23^{\mathrm{b}^{* *}}$ \\
$\mathrm{G}_{6}$ & 6 & $84 \%$ & $6.18 \pm 0.94^{\mathrm{b}^{* *}}$ & $1.54 \pm 0.36^{\mathrm{b}^{* *}}$ \\
$\mathrm{G}_{7}$ & 6 & $88.5 \%$ & $5.60 \pm 0.75^{\mathrm{b}^{* *}}$ & $1.44 \pm 0.32^{\mathrm{b}^{* *}}$ \\
$\mathrm{G}_{8}$ & 6 & $89.5 \%$ & $5.58 \pm 0.70^{\mathrm{b}^{* *}}$ & $1.40 \pm 0.26^{\mathrm{b}^{* *}}$ \\
$\mathrm{G}_{9}$ & 6 & $90.5 \%$ & $5.55 \pm 0.64^{\mathrm{b}^{* *}}$ & $1.37 \pm 0.23^{\mathrm{b}^{* *}}$ \\
\hline
\end{tabular}

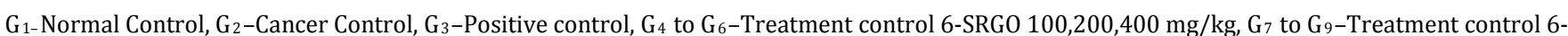
SRGO-LMM 100,200,400 mg/kg, All values are expressed as mean \pm SEM for 6 animals in each group and results were analyzed by using One way ANNOVA, followed by Dunnetts post test, $\mathrm{a}^{* *}$-Values are significantly different from normal control $\left(\mathrm{G}_{1}\right)$ at $\mathrm{P}<0.01$, $\mathrm{b}^{* *}$-Values are significantly different from cancer control $\left(\mathrm{G}_{2}\right)$ at $\mathrm{P}<0.01$

A series of 6-SRGO-LMM were prepared and observed physically for phase separation. In the process of reformulations study, the concentrations of phospholipid and SCH that would give noncoagulation and non-sedimenting mixed micelles were determined. A $3^{2}$ factorial design was taken to optimize their concentrations. The concentration of 6-SRGO was kept constant. As per $3^{2}$ factorial designs, nine different batches of the different concentration ratio of phospholipid and SCH were prepared. The responses obtained from these batches are shown in table 6 . The data obtained was subjected to multiple regression analysis using design expert 10 software.

Table 6: Regression analysis results of measured responses

\begin{tabular}{llll}
\hline Coefficients & Parameters & Encapsulation efficiency \\
\cline { 2 - 4 } & Micelles size & Drug content & 81.55 \\
\hline$\beta_{0}$ & 356.11 & 86.27 & 6.22 \\
$\beta_{1} \beta_{2}$ & 50.33 & -0.47 & 1.61 \\
$\beta_{11}$ & 12.67 & 4.82 & - \\
$\beta_{22}$ & - & - & - \\
$\beta_{12}$ & - & - & -3.60 \\
$\mathrm{r}^{2}$ & - & 0.7656 & 0.8875 \\
\hline
\end{tabular}

The results of multiple regression analysis of the obtained data are summarized in table 6 . The adequacy of fitted model was checked by analysis of variance. To study the interaction effects of the independent variables, response surface plots were constructed using Design Expert 10 software (fig. 7).

From the factorial design study (table 6), it is observed that positive coefficients of the main term X1 and the interaction term X1X1 indicated a favorable effect on the mean micelle size, with the phospholipid chiefly influencing than $\mathrm{SCH}$. The phospholipid had a linear effect on the mean micelles size as seen in surface plot (fig.
7A). Smaller micelles were obtained at low phospholipid content, probably due to high distribution efficiency of an internal phase into external phase [3]. Increase in the viscosity of internal phase with an increased amount of phospholipid also provides resistance for mass transfer during diffusion of an internal phase into the external phase leading to micelles enlargement. The increase in the mean micelles size may also be due to the hydrophobic-hydrophobic interaction of phospholipid with the drug.

Both X1 and X2 showed favorable positive effects on DC and EE. In case of phospholipid, it showed the linear effect on DC and EE. 
Further more in case of SCH it also showed linear effects on DC and EE. As seen in surface plot (fig. 7B, C), the phospholipid favored DC and $\mathrm{EE}$ by hydrophobic-hydrophobic interactions with drugs leading to the formation of interpenetrated network chain. However, $\mathrm{SCH}$ exerted an opposite effect as it led to solubilization of the drug in the external phase.
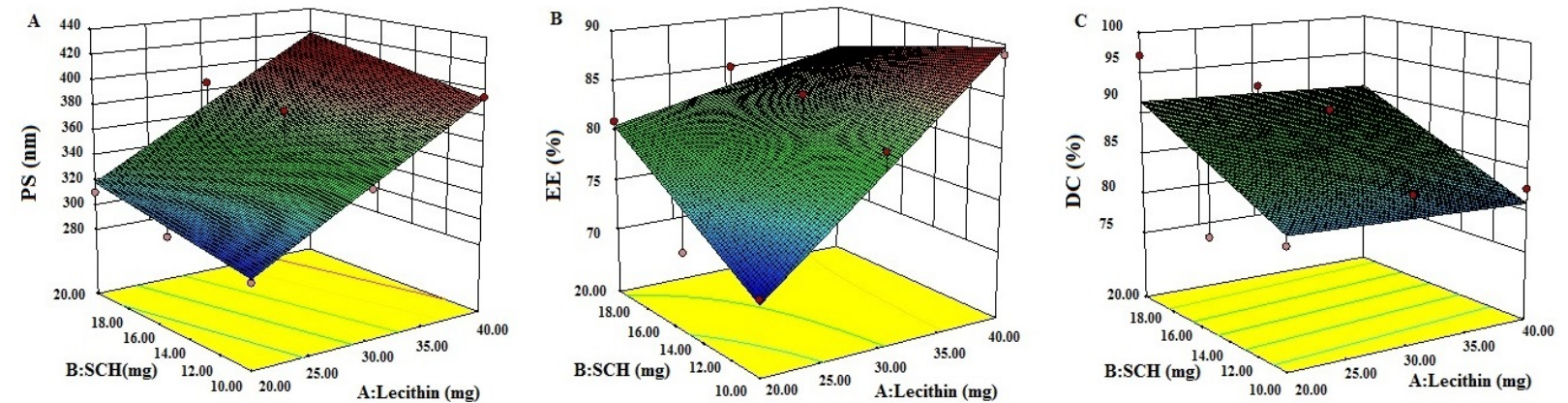

Fig. 7: Response surface plot illustrating effect of factorial variables. (A) Particle size, (B) Encapsulation efficiency, (C) drug content

Based on the results of the factorial design, batch F5 6-SRGO-LMM having acceptable PS, DC and EE was selected as an optimized batch. The size of the optimized 6-SRGO-LMM was $380 \pm 3 \mathrm{~nm}$-which was not significantly different from its blank counterpart. Large molecules of more than $40 \mathrm{kDa}$ in size and certain particles ranging from 10 to $400 \mathrm{~nm}$ can leave the vascular bed and accumulate inside the interstitial space of the tumor (EPR effect) [24]. Drug delivery to specific sites of the body is influenced by the size of the mixed micelles; smaller micelles may tend to minimize the particle uptake by nontargeted cells, including their premature clearance by the mononuclear phagocytic system [38]. It is hypothesized that mixed micelles developed in the present study are of appropriate size to be able to passively target the tumor site.

In the IR spectra of 6-SRGO-LMM does not shows a remarkable peak of an active drug such as $-\mathrm{C}=0$ ketone stretching and $-\mathrm{OH}$ bending, thus final IR spectra of 6-SRGO-LMM revealed that 6-SRGO has been completely encapsulated with phospholipid in the formulation.

According to the DSC results, the melting point of free 6-SRGO was observed at around $240{ }^{\circ} \mathrm{C}$ with the enthalpy $31.11 \mathrm{~J} / \mathrm{g}$. In case of 6SRGO-LMM thermogram, the free 6-SRGO peak was disappeared and shifted to $148{ }^{\circ} \mathrm{C}$ indicating molecular dispersion of 6-SRGO inside mixed micelles. Thermograms of 6-SRGO-LMM show a sharp endothermic peak starting near about at $135^{\circ} \mathrm{C}$ and ending at 155 ${ }^{\circ} \mathrm{C}$. Onset temperature at approximately $135{ }^{\circ} \mathrm{C}$ and melting point around $148.26^{\circ} \mathrm{C}$ are desirable for particle stability at room or lower temperatures and digestibility in the gastrointestinal tract, respectively, acting as a trigger to release the active core during the digestion process [39].

The TEM image shows that there is no drug crystallization appears in the micellar formulations and the surface of the micelles are smooth and they are suspended uniformly in the formulation. The bright region may represent the hydrophilic shell, while the dark region was likely the hydrophobic core of the micelles.

The enhanced in vitro cytotoxic activity of 6-SRGO-LMM may be attributed to greater cellular uptake of micelles via phagocytosis or the fusion process of phospholipid micelles as compare to 6-SRGO [40]. Therefore, 6-SRGO-LMM might have served as a potential nanocarrier to improve the in vitro cytotoxic activity of 6-SGL. The lower anticancer activity of 6-SRGO and blank mixed micelles may be due to their efflux by P-glycoprotein pumps. The above GI50 and LC50 values reveal that the 6-SRGO-LMM gives potential anticancer activity as compared to 6-SRGO.

Acute toxicity study showed that oral administration of 6-SRGO and 6-SRGO-LMM in acute dose up to $2000 \mathrm{mg} / \mathrm{kg}$ body weight did not produce any sign of toxicity or death in mice, suggesting a lethal dose $50 \%$ (LD50) above $2000 \mathrm{mg} / \mathrm{kg}$. An acute toxic study provides a guideline for selecting doses for in vivo study $(1 / 10$ th and $1 / 20$ th of maximum dose in mice) which may be more clinically relevant
[41]. Thus, derived doses of $100 \mathrm{mg} / \mathrm{kg}, 200 \mathrm{mg} / \mathrm{kg}$ and $400 \mathrm{mg} / \mathrm{kg}$ for both 6-SRGO and 6-SRGO-LLPS have been selected.

In DLA tumor, a rise in ascitic tumor volume was noticed. Ascitic fluid gives rise to a direct nutritional source for tumor cells and a sudden rise in an ascitic fluid with tumor growth to meet the nutritional requirement of tumor cells [36]. Treatment with 6-SRGOLMM increased the life span of the mice, controlled the tumor volume and reduced the cell count of the tumor more significantly than the groups treated with 6-SRGO at a dose of at all three doses. The lifespan of the animal after starting the treatment for the cancer is the most reliable criteria to find out the efficacy of the drug used to treat the cancer [42].

Usually, the major problem in the treatment of the cancer is the suppression of myeloma and the anemia $[43,44]$. The anemia arises mainly because of reduction in the RBC count or reduction in the total hemoglobin count [45]. Treatment with 6-SRGO and 6-SRGOLMM at all three doses brought backs all the hematological parameters to the normal level significantly.

Thus the results show that the 6-SRGO-LMM exhibited better antitumor activity against DLA bearing mice as compare to the 6SRGO at all three doses.

\section{CONCLUSION}

We have developed and investigated mixed micelles composed of phospholipids (soya lecithin S80) and $\mathrm{SCH}$ as an effective nanocarrier for the delivery of a natural lipophilic anticancer bioactive 6-SGL from 6-SRGO. The developed 6-SRGO-LMM exhibited higher DC and sustained release of 6-SGL from 6-SRGO. Micellar encapsulation of 6-SRGO resulted in remarkable stability for up to $90 \mathrm{~d}$. Moreover, the 6-SRGO-LMM demonstrated higher in vitro cytotoxic activity in human breast cancer MCF-7 cells and in vivo anticancer activity in DAL cells than 6-SRGO, which may bring about reduction in dose as well as cost. As a result, this 6-SRGO-LMM may be used to add value to new products by increasing anticancer activity, in which 6-SRGO play an important role on the attenuation of complications associated to cancer.

\section{ABBREVIATION}

GO-ginger oleoresin, 6-SGL-6-shogaol, 6-SRGO-6-shogaol rich ginger oleoresin, 6-SRGO-LMM-6-shogaol rich ginger oleoresin-loaded mixed micelles, FTIR-fourier transform infrared spectroscopy, DSCdifferential scanning calorimetry, SCH-sodium cholate hydrated, EPR-enhanced permeability and retention, LMM-loaded mixed micelles, RP-HPLC-reverse phase high performance liquid chromatography, DC-drug content, EE-entrapment efficiency, PSparticle size, TEM-transmission electron microscopy, ACTRECadvanced centre for treatment, research and education in cancer, CPCSEA-committee for the purpose of control and supervision on experimental animals, DAL-dalton's ascitic lymphoma, IAECinstitutional animal ethics committee. 


\section{ACKNOWLEDGMENTS}

The authors are thankful to the University Grant Commission-Basic Scientific Research (UGC-BSR) (File No.: F.4-1/2006 (BSR)/723/2007(BSR) dated January 2013), New Delhi, India for financial assistance to carry out the research work efficiently. The authors also sincerely acknowledge Tata Memorial Center, Advanced Centre for Treatment Research and Education in Cancer, Mumbai, India for the in vitro cytotoxicity study.

\section{AUTHOR CONTRIBUTION}

Kiran Kemkar: Literature survey, data collection and analysis, practical work, drafting the article, writing manuscript.

Dr. Sathiyanarayanan L.: Design of the work, data analysis, critical revision of the article, final approval of the version to be published.

Dr. Arulmozhi Sathiyanarayanan: Design and analysis of animal activity.

Dr. Kakasaheb Mahadik: Final approval of this work and help to get the facility available for the work to be done.

\section{CONFLICT OF INTERESTS}

The authors declare no conflict of interest

\section{REFERENCES}

1. Kelly S, Kevin M, Aranee C, Luis A, Vondel R, Chen L, et al. Microencapsulation of ginger (Zingiber officinale) extract by spray drying technology. Food Sci Technol 2016;70:119-25.

2. Shukla Y, Singh M. Cancer preventive properties of ginger: a brief review. Food Chem Toxicol 2007;45:683-90.

3. Bothiraja C, Kapare H, Pawar A, Shaikh K. Development of plumbagin-loaded phospholipid-Tween ${ }^{\circledR} 80$ mixed micelles: formulation, optimization, effect on breast cancer cells and human blood/serum compatibility testing. Ther Delivery 2013;4:1247-59.

4. Oriania V, Alvimb I, Consolia L, Molinac C, Pastored G, Hubingera M. Solid lipid microparticles produced by spray chilling technique to deliver ginger oleoresin: structure and compound retention. Food Res Int 2016;80:41-9.

5. Singh G, Kapoor Singh P, Heluani C, Lampasona M, Catalan C. Chemistry, antioxidant and antimicrobial investigations on essential oil and oleoresins of Zingiber officinale. Food Chem Toxicol 2008;46:3295-302.

6. Lawal T, Slover C, Lee V, Mahady G. Ginger (zingiber officinale roscoe, zingiberaceae) extract and 10-gingerol enhance the activity of clarithromycin against resistant helicobacter strains. Planta Med 2016;82:5.

7. Jain P, Das D, Singhai AK. Alternative herbal drugs used for treating hair disease. Asian J Pharm Clin Res 2016;9:110-2.

8. Karale P, Karale M. An overview on plants with antiinflammatory potential. Int J Curr Pharm Res 2017;9:1-4.

9. Tyagi R, Sharma G, Jasuja ND, Menghani E. Indian medicinal plants as an effective antimicrobial agent. J Crit Rev 2016;3:69-71.

10. Chen H, Lishuang L, Soroka D, Warin R, Parks T, Hu Y, et al. Metabolism of [6]-shogaol in mice and in cancer cells. Drug Metab Dispos 2012;40:742-53.

11. Wu H, Hsieh M, Lo C, Liu C, Sang S, Ho C, et al. 6-Shogaol is more effective than 6-gingerol and curcumin in inhibiting 12-0tetradecanoylphorbol 13-acetate-induced tumor promotion in mice. Mol Nutr Food Res 2010;54:1296-306.

12. Kim J, Lee S, Park H, Yang J, Shin T, Kim Y, et al. Cytotoxic components from the dried rhizomes of Zingiber officinale roscoe. Arch Pharm Res 2008;31:415-8.

13. Surh Y, Lee E, Lee J. Chemoprotective properties of some pungent ingredients present in red pepper and ginger. Mutat Res 1998;402:259-67.

14. Nikam A, Sathiyanarayanan L, Mahadik K. Mapping pharmacokinetic and tissue distribution profile of [6]-shogaol from ginger oleoresin. Int J Pharm Pharm Sci 2013;5:185-9.

15. Kumar P, Paul W, Sharma C. Green synthesis of gold nanoparticles with Zingiber officinale extract: Characterization and blood compatibility. Process Biochem 2011;46:2007-13.
16. Uthumpa C, Indranupakorn R, Asasutjarit R. Development of nanoemulsion formulations of ginger extract. Advs Appl Mater Electro Eng 2013;684:12-5.

17. Ratcharin N, Wongtrakul P, Indranupakorn R. Preparation of zingiber officinale extract loaded solid lipid nanoparticles. Biomat Appls 2012;506:389-92.

18. Akula NP. Preparation and evaluation of shampoo powder containing herbal ingredients. Asian J Pharm Clin Res 2015;8:266-70.

19. Pituanan BS, Surini S. Fast-disintegrating tablet formulation of ginger (zingiber officinale rosc.) extract using co-processed excipient of pre-gelatinized cassava starch-acacia gum. Int J Appl Pharm 2017;9:77-84.

20. Kulthe S, Inamdara N, Choudhari Y. Mixed micelle formation with hydrophobic and hydrophilic pluronic block copolymers: implications for controlled and targeted drug delivery. Colloids Surf B 2011;88:691-6.

21. Chiappetta D, Hocht C, Opezzo J. Intranasal administration of antiretroviral loaded micelles for anatomical targeting to the brain in HIV. Nanomedicine 2013;8:223-37.

22. Jones M, Leroux J. Polymeric micelles-a new generation of colloidal drug carriers. Eur J Pharm Biopharm 1999;48:101-11.

23. Yoncheva K, Calleja P, Agueros M. Stabilized micelles as delivery vehicles for paclitaxel. Int J Pharm 2012;436:258-64.

24. Gao H, Cao S, Chen C. Incorporation of lapatini b into lipoproteinlike nanoparticles with enhanced water solubility and antitumor effect in breast cancer. Nanomedicine 2013;8:1429-42.

25. Gao Z, Tian L, Hu J. Prevention of metastasis in a $4 \mathrm{~T} 1$ murine breast cancer model by doxorubicin carried by folate conjugated pH-sensitive polymeric micelles. J Controlled Release 2011;152:84-9.

26. Li X, Zhang Y, Fan Y. Preparation and evaluation of novel mixed micelles as nanocarriers for intravenous delivery of propofol. Nanoscale Res Lett 2011;6:275.

27. Tong S, Xiang B, Dong D. Enhanced antitumor efficacy and decreased toxicity by self-associated docetaxel in phospholipid-based micelles. Int J Pharm 2012;434:413-9.

28. Muthu M, Kulkarni S, Liu Y. Development of docetaxel-loaded vitamin E TPGS micelles: formulation optimization, effects on brain cancer cells and biodistribution in rats. Nanomedicine 2012;7:353-64.

29. Saxena V, Hussain M. Poloxamer 407/TPGS mixed micelles for delivery of gambogic acid to breast and multidrug resistant cancer. Int J Nanomed 2012;7:713-21.

30. Nikam A, Sathiyanarayanan L, Mahadik K. Validation of reversed-phase high-performance liquid chromatography method for simultaneous determination of 6-, 8-, and 10shogaol from ginger preparations. Int J Pharm Pharm Sci 2013;5:432-7.

31. Liu J, Zhao X. Design of self-assembling peptides and their biomedical applications. Nanomedicine 2011;6:1621-43.

32. Sathiyanarayanan L, Arulmozi S, Chidhambarnathan N. Anti carcinogenic activity of Leptadenia reticulataI against dalton's ascitic lymphoma. Iran J Pharmacol Toxicol 2006;6:133-6.

33. Unnikrishnan $M$, Kuttan $R$. Tumor reducing and anticarcinogenic activity of selected species. Cancer Lett 1990;51:85-9.

34. Jiang-nan Y, Yuan Z, Li W, Min P, Shan-shan T, Xia C, et al. Enhancement of oral bioavailability of the poorly water-soluble drug silybin by sodium cholate/phospholipid-mixed micelles. Acta Pharmacol Sin 2010;31:759-64.

35. Rupp C, Steckel H, Muller B. Mixed micelle formation with phosphatidylcholines: the influence of surfactants with different molecule structures. Int J Pharm 2010;387:120-8.

36. Prasad S, Giri A. Antitumor effect of cisplatin against murine ascites Dalton's lymphoma. Indian J Exp Biol 1994;32:155-62.

37. Bhattarai S, Tran V, Duke C. Stability of [6]-gingerol and [6]shogaol in simulated gastric and intestinal fluids. J Pharm Biomed Anal 2007;45:648-53.

38. Brigger I, Dubernet C, Couvreur P. Nanoparticles in cancer therapy and diagnosis. Adv Drug Delivery Rev 2002;54:631-51.

39. Tulini F, Souza V, Echalar-Barrientos A, Thomazini M, Pallone E, Favaro-Trindade C. Development of solid lipid microparticles loaded with a proanthocyanidin rich cinnamon extract 
(Cinnamomum zeylanicum): Potential for increasing antioxidant content in functional foods for diabetic population. Food Res Int 2016;85:10-8.

40. Koo O, Rubinstein I, Onyuksel H. Camptothecin in sterically stabilized phospholipid micelles: a novel nanomedicine. Nanomedicine 2005;1:77-84.

41. Mehta A, Arora N, Gaur S, Singh B. Acute toxicity assessment of choline by inhalation, intraperitoneal and oral routes in Balb/c mice. Regul Toxicol Pharmacol 2009;54:282-6.
42. Clarkson B, Burchenal J. Preliminary screening of antineoplastic drugs. Prog Clin Cancer 1965;1:625-9.

43. Price V, Greenfield R. Anemia in cancer. Adv Cancer Res 1958;5:199-200.

44. Hogland H. Hematological complication of cancer chemotherapy. Semin Oncol 1982;9:95-102.

45. Fenninger L, Mider G. Energy and nitrogen metabolism in cancer. Adv Cancer Res 1954;2:229-53. 